\title{
Educando pesquisadores qualitativos em saúde no Brasil: perspectivas discentes e docentes
}

\author{
I ${ }^{1}$ Maria Inês Gandolfo Conceição, 2 Denise Gastaldo, ${ }^{3}$ Alex Branco Fraga, \\ ${ }^{4}$ Maria Lucia Magalhães Bosi, ${ }^{5}$ Lilian Magalhães, ${ }^{6}$ João Tadeu de Andrade, \\ ${ }^{7}$ Rozilaine Redi Lago I
}

Resumo: Embora em franca expansão, a pesquisa qualitativa enfrenta desafios no campo da saúde. O objetivo é analisar o ensino de pesquisa qualitativa em saúde na pósgraduação no Brasil na perspectiva de atores envolvidos no processo, visando compreender desafios e possibilidades na formação de futuros pesquisadores. Foram conduzidos três grupos focais, totalizando 37 participantes no espaço de um congresso de pesquisa qualitativa em saúde. Emergiram quatro categorias na análise: campo científico biomédico; produtivismo e avaliação acadêmica; estratégias de ensino e currículo e formação de educadores. Os resultados revelam desafios na formação de pesquisadores em pesquisa qualitativa no Brasil num campo científico dominado pela tradição positivista, baixo letramento de cientistas em métodos qualitativos e predomínio da cultura acadêmica produtivista. Conclui-se que o preconceito dificulta a formação de novos pesquisadores, mas há iniciativas de excelência na formação, como o ensino obrigatório dessa abordagem na graduaçáo e o ensino interdisciplinar na pós-graduação.

> Palavras-chave: pesquisa qualitativa; formação de pesquisadores; ensino; produtividade científica.

\author{
${ }^{1}$ Universidade de Brasília. \\ Brasília-DF, Brasil (inesgandolfo@ \\ gmail.com). \\ ORCID: 0000-0002-4052-3813 \\ ${ }^{2}$ University of Toronto. Toronto, \\ Canada (denise.gastaldo@ \\ utoronto.ca). \\ ORCID: 0000-0003-3001-7981 \\ ${ }^{3}$ Universidade Federal do Rio \\ Grande do Sul. Porto Alegre-RS, \\ Brasil (brancofraga@gmail.com). \\ ORCID: 0000-0002-6881-1446 \\ ${ }^{4}$ Universidade Federal do Ceará. \\ Fortaleza-CE, Brasil (malubosi@ \\ ufc.br). \\ ORCID: 0000-0001-9742-9230 \\ ${ }^{5}$ Universidade Federal de São \\ Carlos. São Carlos-SP, Brasil \\ (Imagalhaes@ufscar.br). \\ ORCID: 0000-0003-3666-3685 \\ ${ }^{6}$ Universidade Estadual do \\ Ceará. Fortaleza-CE, Brasil (joao. \\ andrade@uece.br). \\ ORCID: 0000-0003-0371-5135 \\ ${ }^{7}$ Universidade Federal do Acre. \\ Rio Branco-AC, Brasil (rozilainee@ \\ gmail.com). \\ ORCID: 0000-0002-1383-0463
}


A abordagem qualitativa vem sendo, cada vez mais, difundida no âmbito da atividade científica no campo da saúde (MERCADO; BOSI, 2010). O termo "qualitativo" se refere aqui a um enfoque no qual se incluem diversas tradiçôes e subtradições (PRASAD, 2005; MALTERUD, 2016), devendo toda pesquisa efetivamente qualitativa contemplar os planos ontológico, epistemológico, metodológico e ético, não se restringindo ao mero emprego de técnicas. Da congruência entre esses planos ou camadas deriva a qualidade e o rigor. A pesquisa qualitativa está enraizada nas ciências humanas e sociais e se volta ao desvelamento dos modos como o mundo social é compreendido em sua diversidade, ou seja, como as pessoas o vivenciam, interpretam suas experiências mediante a construção de significados individuais e coletivos, interpretaçoes, práticas, comportamentos e processos sociais (FACEY; GLADSTONE; GASTALDO, 2018).

A pesquisa qualitativa é favorecida tanto pelo avanço dos conhecimentos e de soluções técnicas, quanto pelo desenvolvimento do componente humano nas açôes em saúde (MERCADO; GASTALDO; PRADO, 2018). Contudo, apesar do crescimento e reconhecimento alcançados, o enfoque qualitativo ainda enfrenta um conjunto de desafios para sua afirmação plena nos vários domínios do campo científico. Nesse contexto, a área da saúde experimenta dificuldades singulares e, por vezes, extremas, dada a interdisciplinaridade dessa abordagem voltada aos processos intersubjetivos que confrontam incisivamente o crivo positivista hegemônico no campo da saúde (BOSI, 2012a; EAKIN, 2016). Noutras palavras, a pesquisa qualitativa em saúde (PQS) explicita a subjetividade subjacente aos princípios norteadores do Sistema Único de Saúde (SUS) como: qualidade; humanização, equidade; integralidade; participação, dentre outros vinculados à Reforma Sanitária Brasileira (LIMA; SANTANA, 2006; PAIM, 2006) e representa um dispositivo de grande valia ao gerar saberes para enfrentar os desafios que se impóem à consolidação da reforma sanitária e efetivação do SUS (PAIM, 2006) através da criação de mecanismos inovadores de qualificação de trabalhadores da saúde.

Contudo, a falta de oportunidades de formação na PQS no Brasil expressa um dos efeitos da hegemonia do modelo da biomedicina (SILVA, CASTRO-SILVA, MOURA, 2018). Uma rápida consulta às estruturas curriculares dos programas de Pós-graduação do campo Saúde Coletiva (considerado como aquele que mais articula o biológico e o social na saúde), realizada a título de exploração não sistemática no decurso desta análise, confirma a assertiva de Bosi (2015) de que "o ensino do 
enfoque qualitativo ainda se mostra frágil e ocasional, o que [...] leva a interrogar se em um campo assumidamente interdisciplinar (trans?) tal pluralidade epistêmica se expressa na formação" (p. 165). Tal situação, ao que parece, se multiplica nas demais pós-graduaçóes no campo da saúde, ainda com mais força. Se o legado naturalista do conhecimento em saúde tem uma contribuição inegável, tampouco se pode ignorar o diálogo fértil entre pesquisadores qualitativos neste campo e os aportes teóricometodológicos das ciências humanas e sociais, nos quais o arcabouço epistemológico da PQS se fundamenta (CHIZZOTTI, 2008; PACKER, 2011; POUPART et al., 2010). Essa posição no campo científico acarreta e decorre de dificuldades, como advertem Webster et al. (2019, p. 3): “cientistas da saúde frequentemente enfrentam barreiras institucionais para contratação e promoção porque fazem ciência de maneira diferente, o que significa envolver-se com percepçôes, narrativas, intersubjetividade, práticas culturais, estruturas sociais e relaçōes de poder ao estudar saúde e doença”. Essa posição reproduz o que se verifica no campo científico, em seu conjunto, se analisados seus dispositivos: editais de fomento; premiações; número de pesquisadores contemplados com bolsas de produtividade em pesquisa, além do fato exemplar de só em 2016 ter sido aprovada a Resoluçáo no 510/2016 - Ética na Pesquisa na área de Ciências Humanas e Sociais, ou seja, 30 anos após a Resolução no 196/96.

A despeito da importância da PQS, a escassez de pesquisadores no campo do ensino e da pesquisa em saúde, tanto em termos quantitativos (se comparada à pesquisa básica e epidemiológica), como também no que tange à experiência acumulada (pesquisadores seniores) é muito expressiva no Brasil. Também é baixa a disponibilidade de profissionais com formação sólida necessária à nucleação de grupos que tenham extensos programas de pesquisa; realização de pesquisas de alta qualidade e orientação de mestres e doutores, como demonstra a literatura (BOSI, 2012a; SILVA, CASTRO-SILVA, MOURA, 2018).

Assim, em resposta à precariedade de oportunidades de formação, um grupo de pesquisadores vêm discutindo açôes necessárias para ampliá-las. Esses pesquisadores de distintos campos disciplinares, atuantes em universidades das cinco regiôes brasileiras, em parceria com a University of Toronto, onde se localiza um dos mais importantes centros de excelência nesse enfoque (Centre for Critical Health Qualitative Health Research - CCQHR), unem-se neste artigo visando analisar os desafios e possibilidades do ensino da pesquisa qualitativa em saúde, na perspectiva de atores envolvidos nesse processo, suprindo uma lacuna na discussão 
relativa ao tema que vem sendo analisado sem a mediação discursiva dos segmentos participantes deste estudo.

\section{Biomedicina, produtivismo científico e a formação de pesquisadores qualitativos}

No Brasil, o modelo biomédico tem sido responsabilizado por dificuldades crônicas nos serviços de saúde e na formação profissional. Embora historicamente venha investindo na tentativa de superar a lógica biomédica, o SUS enfrenta desafios para a construção do modelo humanizado e biopsicossocial de atenção à saúde (ALMEIDA; CONCEIÇÃO, 2015). Paradoxalmente, os profissionais são formados nas universidades brasileiras com base em um modelo predominantemente tradicional, mas deles são exigidos uma atuação inovadora e flexível (ALMEIDA FILHO, 2010). De acordo com Campos (2011, p. 1270), “o paradigma predominante na ciência contemporânea parece desconhecer a atual conjuntura de mudança social acelerada e a intensa diversificação das esferas da vida que não podem ser estudadas pela via dedutiva clássica".

Barros (2002) acredita que, apesar do avanço e sofisticação da biomedicina, esta não é capaz de fornecer respostas para problemas associados a doenças com marcado componente psicológico ou subjetivo. $\mathrm{O}$ autor acredita que há despreparo dos profissionais diante desses casos e que, embora reconheçam a influência de componentes subjetivos, não parecem questionar a noção de objetividade com a qual foram treinados. "De fato, o modelo biomédico estimula os médicos a aderir a um comportamento extremamente cartesiano na separação entre o observador e o objeto observado" (BARROS, 2002, p. 79), o que dá sustentação ao preconceito em relação aos modelos científicos das ciências sociais e humanas que trabalham objetividade e subjetividade desde outra perspectiva epistemológica.

Paralelamente à crise do modelo cartesiano na formação profissional, a pósgraduação brasileira vem sendo submetida à lógica capitalista nos últimos anos e tem adotado um modelo de organização do trabalho que associa o discurso da flexibilidade com a rigidez das metas de produtividade (BERNARDO, 2014). Essa perspectiva desconsidera a essência da educação como bem público e a toma como produto mercadológico. Nessa esteira, a avaliação do trabalho docente na pós-graduação tem sido numérica, isto é, baseia-se na quantidade de artigos 
publicados em revistas com fator de impacto determinado por empresas privadas, número de orientações, horas-aula e prazos de conclusão de mestrados e doutorados (BOSI, 2009; GASTALDO; BOSI, 2010). Bernardo (2014) alerta para as graves consequências desse "capitalismo acadêmico" que se traduz na precarização do trabalho. Internacionalmente, já se constata como efeitos a precariedade subjetiva, o desgaste mental, o sofrimento psíquico e o adoecimento de docentes e discentes da pós-graduação (BERG; SEEBER, 2013).

A política do "publish or perish", associada à hegemonia positivista que determina o padrão de cientificidade biomédica, prejudica a evolução e a expansão das pesquisas qualitativas (CHAPELA, 2018). De acordo com Campos (2011), considerando-se as normas baseadas em princípios quantitativos que exigem artigos curtos (nas revistas no topo do ranking da Web of Science), a maioria dos artigos intitulados qualitativos no Brasil limita-se a fórmulas lacônicas e pouco explicativas, tais como: "realizamos um estudo com análise de conteúdo" ou, "extraímos as categorias emergentes do material” (CAMPOS, 2011, p. 1272). O estudo bibliográfico realizado por Ramos et al. (2010), com base em artigos de pesquisas qualitativas de uma revista brasileira de Saúde Coletiva, revela que mais da metade dos artigos identifica o desenho de pesquisa qualitativa pelo uso da técnica empregada no trabalho de campo, tal como entrevista, observação e grupo focal.

A formação de pesquisadores qualitativos molda-se pelas influências sociais e culturais descritas acima, por isso a necessidade de entender esse contexto. Autores que investigam a formação de pesquisadores qualitativos em saúde destacam que essa empreitada deve extrapolar o ensino de técnicas de geração e análise de dados (MERCADO; GASTALDO; PRADO, 2018; SILVA; CASTRO-SILVA; MOURA, 2018). Chizzotti (2008) descreveu tal aprendizado como "a possibilidade de se traduzir a experiência humana em um texto” (p. 231). Para Holligan (2015), a capacidade de realizar pesquisas qualitativas pode ser descrita como a transferência de capital simbólico entre mestres e estudantes, nos termos propostos por Bourdieu (2011), ou seja, um aprendizado complexo que permita compartilhar capital cultural, científico e social. Essa posição é similar ao que propõe Eakin (2016) quanto ao papel dos contextos institucionais nos quais se desenvolve a formaçáo de pesquisadores:

$\mathrm{O}$ ensino de metodologia qualitativa é moldado de maneira crucial pelo contexto institucional mais amplo em que está situado, incluindo as estruturas organizacionais e ideologias associadas à distribuição de financiamento de pesquisa e apoio aos estudantes, 
às demarcaçóes e inter-relaçóes de acadêmicos e disciplinas profissionais, às políticas de financiamento e aos modos de gestáo de formação profissional na universidade (p. 108, traduçáo nossa).

A autora justifica a necessidade de consolidação de projetos ousados transgressivos - de ensino de metodologia qualitativa, sustentando a necessidade de fomentar o intercâmbio sistemático de experiências entre pesquisadores e estudantes de vários níveis de expertise no campo (EAKIN, 2016).

A predominância da tradição de pesquisa quantitativa na formação dos profissionais de saúde no Brasil, presente desde os cursos de graduação, conduz ao cenário hegemônico desse paradigma no âmbito da pós-graduação, onde há pouco espaço para o avanço da abordagem qualitativa (SILVA; CASTRO-SILVA; MOURA, 2018). Na formação para a pesquisa qualitativa em pós-graduação, de modo geral, os alunos vão aprendendo a pesquisar principalmente por orientação individual, dada a ausência de uma estrutura curricular para sua formação (SILVA; CASTRO-SILVA; MOURA, 2018; VILLARDI; VERGARA, 2011). Assim, a elaboração da pesquisa qualitativa normalmente é feita de forma intuitiva pelos pesquisadores iniciantes (SILVA; CASTRO-SILVA; MOURA, 2018), sendo para muitos uma perspectiva completamente nova, já que sequer tiveram a oportunidade de conhecer essa abordagem na graduação. Ainda que isso seja uma prática comum no Brasil, o mesmo não ocorre em outras realidades nas quais há treinamento formal de desenvolvimento de jovens pesquisadores (GASTALDO, 2012).

Este estudo tem por objetivo analisar o estado da arte sobre o ensino de pesquisa qualitativa em saúde a partir das perspectivas de discentes e docentes vinculados ao ensino e prática da pesquisa qualitativa em saúde no Brasil para subsidiar a compreensão dos desafios e possibilidades nessa área.

\section{Metodologia}

Conforme já assinalado, todos os procedimentos técnicos aqui relatados, bem como o exercício analítico se afiliam ao paradigma interpretativo, e se ancoram nos fundamentos da tradiçẫo da hermenêutica crítica que, por limites de espaço, náo serão detalhados. Este estudo utiliza uma metodologia qualitativa crítica (BAUMAN, 2008; BOSI, 2012b; BOURDIEU, 1983; FACEY, GLADSTONE; GASTALDO, 2018; CENTRE..., 2018), com a finalidade de compreender e problematizar a experiência educacional em pesquisa qualitativa em saúde de discentes 
e docentes brasileiros e propor alternativas para a melhora dessa formação. $\mathrm{O}$ fato de focalizarmos os procedimentos de campo não deve ser, portanto, entendido como "redução do método à técnica" (MERCADO; BOSI, 2010) mas uma estratégia de exposição face aos limites de extensão.

Durante o VIII Congresso Ibero-Americano de Pesquisa Qualitativa em Saúde, em oficina intitulada "Ensino de Pesquisa Qualitativa na Área da Saúde: realidades e propostas para o Brasil e Ibero-América”, ocorrido no dia 5 de setembro de 2018, em Florianópolis, três grupos focais com um total de 37 congressistas foram realizados pelos autores (ABF, DG, JTA, LVM, MIG). A escolha desse evento se deve ao fato de ele reunir centenas de pesquisadores de investigação qualitativa em saúde na Ibero-América, com uma forte presença de brasileiros.

As participantes, na sua maioria mulheres discentes e docentes de pós-graduação na área de saúde de todas as regióes do país, foram orientadas, através de uma breve apresentação, sobre os objetivos do grupo focal e do caráter voluntário da participação no mesmo, cuja aceitação foi unânime. Para promover a diversidade regional de participantes nos grupos, os pesquisadores as distribuíram em dois grupos de 12 participantes e um grupo de 13, com 11 brasileiras e dois professores latino-americanos, que conheciam bem o contexto nacional. Originariamente, esperávamos ter dois grupos de brasileiros e um de latino-americanos, mas como a presença era condicionada à inscrição dos mesmos nessa oficina, os três grupos tiveram como foco o ensino da pesquisa qualitativa em saúde no Brasil.

A condução de dois grupos focais (BARBOUR; KITZINGER, 1999; KRUEGER, 1997) ficou a cargo de uma dupla de moderadores (ABF/MIG e LM/JTA) e um dos grupos teve apenas uma moderadora (DG). O roteiro de discussão centrou-se no ensino da pesquisa qualitativa em saúde almejado, as barreiras para atingir-se tal qualidade e possíveis estratégias de melhoria a curto e médio prazo. A atividade teve duração média de 1 hora e 40 minutos, com excelente engajamento das participantes, que através de linguagem corporal e discussôes demonstraram interesse nos tópicos discutidos, corroboraram ideias e construíram consenso entre os membros do grupo. Não houve diferenças ou discordâncias relevantes entre as participantes, nem entre os temas tratados nos três grupos. Consideramos que o ambiente acolhedor do evento e seu caráter interdisciplinar favoreceram a expressão livre das percepçôes das participantes, reunindo exemplos de diversas disciplinas, com experiências institucionais também 
diversas, de todas as regiōes do país, demonstrando um significativo capital cultural. A contribuição qualificada expressada por essas participantes assegurou a qualidade dos dados gerados neste estudo.

Os três grupos focais foram gravados, transcritos integralmente e a transcrição foi validada por pesquisadores independentes; o software MAXQDA foi utilizado no processamento das informaçóes. Conduzimos uma análise temática (BRAUN; CLARKE, 2006) através da utilização de elementos indutivos (ideias originais dos participantes) e dedutivos (concepçôes teóricas e elementos da literatura atual). Iniciamos pela codificação feita por duas pesquisadoras (MIG e MLB) e verificação por todos os pesquisadores. Dada a extensão dos temas, uma autora (DG) condensou as temáticas e refez subcategorias, que uma vez verificadas pelos demais autores, foram utilizadas para organizar a estrutura deste artigo. Foram construídas quatro categorias analíticas centrais: 1) campo científico biomédico; 2) produtivismo e avaliação acadêmica; 3) estratégias de ensino e currículo e 4) formação de educadores.

Ao longo do processo de pesquisa, foram resguardados todos os aspectos éticos previstos na resoluçáo CNS no 466/2012, incluindo a aprovação do projeto de pesquisa no Comitê de Ética (CAAE 91925818.4.1001.5540) e o consentimento informado por todas as participantes.

\section{A pesquisa qualitativa em saúde no contexto do campo científico biomédico}

$\mathrm{Na}$ área da saúde, o posicionamento da pesquisa qualitativa no campo científico é ainda precário. As participantes mencionaram um conjunto de limitaçôes relacionadas a esta condição, destacando três dimensóes principais. A primeira trata da falta de conhecimento e reconhecimento, a fragilidade do valor e a distribuição desigual de fomento para essa área de pesquisa dentro da pós-graduação. Nesse quesito, as participantes destacaram o pouco espaço destinado à pesquisa qualitativa no ensino e nos projetos de pesquisa desenvolvidos nos programas de pós-graduação, exemplificado pela dificuldade de ingresso de tais estudos, baixo número de pesquisadores, disciplinas e financiamento.

Se você vai pra um projeto qualitativo num programa que é centralmente quanti, você não vai entrar.

De um departamento que tem setenta professores, somente três trabalham pesquisa qualitativa. 
Eu ouvia de colegas: "ah, não, essa disciplina [pesquisa qualitativa] não é tão importante [...]", sempre [com] um menosprezo pela disciplina e aquilo me incomodava muito, inclusive os alunos também diziam: "eu quero só passar nessa disciplina."

Em relação ao financiamento das pesquisas qualitativas, a gente tem mais dificuldade de conseguir financiamento com fundaçóes de amparo à pesquisa porque as pessoas que avaliam nosso trabalho dentro da área não compreendem muito bem o que a gente está fazendo.

A segunda dimensão refere-se a uma postura de desconfiança sobre a cientificidade da pesquisa qualitativa, relacionada ao baixo letramento científico em saúde no que se refere ao domínio do qualitativo. Essa escassez de conhecimentos está associada a ênfase e priorização da formação de pesquisadores orientada pelo paradigma positivista, particularmente a epidemiologia. As participantes assinalam que as políticas editoriais das revistas, que vão desde os altos custos envolvidos na publicaçáo (que atinge os pesquisadores dos diferentes subcampos mas não sem distinção), à desvalorização atribuída aos manuscritos de pesquisas qualitativas, abrangendo ainda a falta de revistas bem qualificadas na área e a ausência de avaliadores versados na tradição qualitativa. Não raro, são reportados pela comunidade qualitativa equívocos impressionantes advindos da escassez de revisores e da precária formação no enfoque, mais um efeito da hegemonia do modelo biomédico na saúde, como ilustram estes excertos:

[...] nós não temos pareceristas quali, portanto a gente também já ouviu isso: "Vai pra epidemio, se tu não consegue pesquisar". Eu digo: "tu tá querendo que eu mude de vida", isso não é sério de você ouvir de um colega, que você tem que mudar completamente o teu fazer; é uma incompreensão tal, que estamos num limite.

Por exemplo, há uma escassez de revisores qualificados no enfoque qualitativo. Tal situação vem gerando muitos problemas, pois se estabelece uma arguição ao enfoque qualitativo com base em critérios do positivismo, exigindo-lhe o que não procede em termos epistemológicos. Mais que isso, os efeitos políticos das disputas epistemológicas no campo (BOURDIEU, 1983) desqualificam o enfoque qualitativo que, por vezes, é barrado na entrada:

Então é muito difícil, já chega recusado, não vai nem pra parecerista, os editores mesmo já excluem o seu trabalho por ser uma pesquisa qualitativa, por ter muita demanda.

Eu percebo nos próprios professores um pouco de insegurança sobre o próprio cunho científico da pesquisa qualitativa em relação à quantitativa.

[Um] docente que tem uma trajetória totalmente quantitativista questionou a cientificidade do projeto da minha aluna. Assim que terminou a aula, ela me procurou e até 
chorou [dizendo]: “O que a gente está fazendo?” [...] Aí eu tive que ter todo um trabalho [para apoiá-la]; foi desgastante.

Além das dimensôes anteriores, as participantes apontaram uma terceira relacionada à complexidade presente no desenvolvimento da PQS. Aqui foi destacada a difícil tarefa de conduzir a pesquisa qualitativa, contrariando o senso comum de se tratar de um trabalho de menor complexidade. Aliada à dificuldade que essa modalidade de pesquisa pressupóe, as participantes também salientaram a necessidade de uma fundamentação epistemológica sólida que favoreça tanto a legitimidade quanto a relevância da pesquisa qualitativa no campo científico:

Quando [os estudantes] se deparam com as primeiras aulas, se impactam [dizendo]: "Como é difícil! Eu não sabia que tinha que ler tanto assim. Eu não sabia o quão difícil é entender algumas questôes”.

[...] [ressalto] a importância dos estudantes terem acesso às concepçôes teórico-filosóficas, as correntes de pensamento, para se fundamentar, e que eles consigam, a partir do seu objeto de estudo, fazer essa opçáo [...] no seu processo de construção do conhecimento.

Em relação às práticas bem-sucedidas da pesquisa de abordagem qualitativa no campo científico, foi enfatizada a atuação conjunta de professores com formação nas abordagens de pesquisa qualitativa e quantitativa. Além disso, ressaltou-se o papel facilitador de alguns epidemiologistas ao reconhecer as possibilidades de a pesquisa qualitativa responder a questôes que não conseguem ser abordadas com as ferramentas da pesquisa quantitativa.

Quando ela [professora] apresenta um design epidemiológico [na aula], ela diz assim:

"Vocês vão ter esses resultados com essa pesquisa, mas daí o porquê isso é assim? Qual é a subjetividade? [Isso] vocês irão pesquisar com a [abordagem] qualitativa”.

A gente tem feito uma parceria colaborativa entre os professores [de pesquisa qualitativa e de quantitativa]. Isso tem mostrado um pouco desse respeito dos professores.

No tocante aos desafios impostos à formação em pesquisa qualitativa em relação ao campo científico, foram elencadas questôes desde a necessidade de aprofundamento teórico e epistemológico na formação de pesquisadores no nível de graduação, até aspectos da gestão do programa de pós-graduação, como o descompasso entre a avaliaçấo do programa e o desenvolvimento e prioridade dessa abordagem dentro dele.

Hoje a nossa universidade é bem conceituada, é uma universidade que está à frente, mas a pesquisa qualitativa ainda está engatinhando.

Então aumentou o conceito [do programa de pós-graduação] pela CAPES, e eles estão dando prioridade às pesquisas quantitativas e não às pesquisas qualitativas. 
Em se tratando da disputa pelo capital simbólico de explicação da realidade, a pesquisa qualitativa em saúde desafia a abordagem positivista em um campo científico dominado por conceitos e estruturas de pesquisa de caráter biomédico, sendo fortemente penalizada neste confronto (BOURDIEU, 2004). Nesse âmbito, o crivo positivista desqualifica o uso de outros sistemas de expressão de "fazer ciência diferentemente", se estes não utilizam os recursos da quantificação (WEBSTER et al., 2019). Superar essas vicissitudes requer uma sólida formação de pesquisadores que precisam dominar o uso de teorias sociais e da reflexividade metodológica capazes de conferir a congruência onto-epistemológica inerente a pesquisas qualitativas de elevada qualidade (GASTALDO, 2018). O resultado dessa disputa por capital simbólico no campo da saúde desfavorece a consolidação do enfoque qualitativo em sua totalidade, haja vista o conjunto de elementos que operam na legitimação dos distintos paradigmas, conforme discutidos no tópico a seguir.

\section{Produtivismo e avaliação acadêmica}

A sobrevivência dos programas de pós-graduação e a garantia de sua sustentabilidade, em face do crescente desinvestimento e da hegemonia da ideologia produtivista (BOSI, 2018) nos processos avaliativos, monopolizam o tempo e a atenção, exercendo influência sobre a "escolha" dos docentes, uma vez que determinados paradigmas são mais valorizados e "eficientes" sob a égide do produtivismo. Acrescente-se a indução operada pelos editais de agências de fomento, nos quais, grosso modo, são raras as linhas que permitem o desenvolvimento de pesquisas qualitativas. Isso se desdobra na escassez de docentes e orientadores no paradigma interpretativo (CHAPELA, 2018). Cabe lembrar que as instâncias que definem as chamadas "prioridades" nas agendas de ciência e tecnologia raramente contam com pesquisadores da tradição, fazendo com que se retroalimentem as posiçôes de poder no campo científico (BOURDIEU, 2004). Assim, se um programa ou pesquisador não se submete a tais exigências e enquadres, corre o risco de se ver excluído do sistema. As participantes descreveram essa situação da seguinte forma:

[...] os programas de pós-graduação precisam atender a esses critérios e, por conta disso, isso vira uma paranoia. Isso tem nos travado bastante, porque há uma exigência muito grande de produçáo científica e a produção significa você ter algo que vai [...] ter um sentido para que as revistas possam ter interesse na publicação e isso trava todo o processo. 
Bosi (2012b), analisando a lógica produtivista e seus impactos na pesquisa qualitativa, adverte:

Retomando-se o critério preponderante de avaliação científica centrado no número de
publicaçóes científicas em periódicos internacionais de elevado impacto, há [...] barreiras
de acesso aos periódicos estrangeiros por parte da produçáo científica do assim chamado
Terceiro Mundo. [...] muito mais difícil é inserir discussôes acerca de aspectos qualitativos
da saúde [...] (2012b, p. 2389).

Tais dificuldades evidenciam-se de forma contundente nos depoimentos das participantes ao destacarem o desinteresse por determinados domínios (ou especialidades) "pouco lucrativos", entenda-se, aqueles que, em geral, demandam teorização e crítica e resistem à lógica da produção seriada que o modelo produtivista traslada do ambiente industrial para a ciência:

Então, toda essa discussão de epistemologia, toda essa discussão do que que se necessita, construção mesmo do pensamento, é, isso tudo fica no segundo, terceiro plano dentro da pós-graduação. Lá a nossa vivência tem sido essa, e isso tem sido barreira, mas isso tem sido também uma utopia de que a gente possa sair dessa camisa de força e pensar numa produção científica em outros moldes.

[...] a tragédia é a questão do Qualis, da cobrança da produção científica.

O sistema Qualis, ao considerar aspectos como fator de impacto e outras dimensôes que geram iniquidades nos processos avaliativos, asfixia possibilidades de publicação. Revistas muito valorizadas nas chamadas “áreas madrinhas", ou seja, aquelas afins aos objetos, podem descer quatro patamares ao serem consideradas em outras áreas. São vários os casos, ao se considerar, citando apenas um exemplo, o contraste entre Saúde Coletiva e Medicina 1. Desse modo, gera-se uma hierarquia entre periódicos que, em boa parte dos casos, não se fundamenta na qualidade, mas nos parâmetros produtivistas que servem à indústria das publicaçôes (KERRPONTES et al., 2005; METZE, 2010). Sabe-se que há vários exemplos de revistas de elevadíssima qualidade sob a ótica dos textos que veiculam, mas por serem do campo das ciências humanas e sociais, não podem competir com revistas biomédicas. Igualmente, o "produto" livro é desvalorizado, quando deveria ser o melhor veículo para publicação de trabalhos extensos e muito exigentes em termos de tempo e investimento intelectual (LUZ, 2005b). Acrescente-se o aspecto éticopolítico relativo à comunicação dos resultados junto ao público de interesse:

[...] Tem algumas revistas que são mais voltadas pra alimentação, pra antropologia da alimentação com avaliação boa, com A1. Mas esse sistema [...] avaliativo da CAPES impede 
bastante [...] porque a gente poderia publicar em uma revista de antropologia, por exemplo, ou outra revista da área de humanas e ciências sociais; às vezes, pra gente é mais interessante publicar nessas revistas do que publicar numa revista em que a maior parte dos artigos é quantitativa e, às vezes, não tem tanto acesso a quem a gente deseja comunicar, né?

As falas das participantes também remetem a preocupações em relação à saúde dos pesquisadores sujeitos a essa lógica produtivista. Expressóes como "tragédia", "paranoia", "cansaço", “adoecimento", "luta insana” sobressaem nas falas de algumas participantes quando estas se referem aos desafios da produção na pós-graduação.

Nós sabemos essa importância, mas é uma luta assim, insana, né? [...] eu tô falando de professores, jovens professoras que já estáo cansadas, e sim, estão buscando se integrar com grupos da epidemio por uma questáo de sobrevivência; [...] ou a gente realmente publica pra tá dentro do jogo... [ou tá fora]. E isso que a gente tá fazendo.

Essa percepção é corroborada por autores internacionais (BERG; SEEBER, 2013) e nacionais, como Luz (2005a) e Bosi (2012b), que ressaltam:

[...] o sofrimento dos intelectuais, o desencantamento do trabalho científico, o adoecimento dos pesquisadores, em um contexto que incentiva o quanto mais, melhor; muitas vezes não importando como ou para que, sendo esta a essência do que aqui se considera produtivismo (BOSI, 2012b, p. 2388).

Também se evidenciou uma especificidade da pesquisa qualitativa, qual seja, sua diferença dos padróes da pesquisa tradicional na saúde, requerendo outro ritmo para que o produto alcance e espelhe a devida qualidade e amadurecimento. $\mathrm{O}$ ritmo veloz produtivista conflita com a necessária construção de um quadro teórico denso e congruente de modo a conferir rigor. Aqui vale a advertência de Bourdieu (2011) quando afirma que a pressa desfavorece a reflexão. Como explicou uma participante:

[...] e eu percebi assim, tanto dos meus colegas quanto das minhas colegas que estavam em formação, uma pressão pra gente defender logo, defender logo, e às vezes eu penso que a gente precisa de um tempo maior também pra se aprofundar naquele estudo que a gente está fazendo, no referencial teórico [...] eu acho que isso acaba [...] fragilizando alguns estudos pela falta de aprofundamento.

Soma-se a isso o fato de os produtos derivados dos estudos não se traduzirem em numerosos artigos, como pode ser o caso de estudos quantitativos.

[...] mas é a dificuldade no processo, porque eu faço um estudo clínico, d'um estudo clínico eu tiro dez artigos, por exemplo, e numa pesquisa qualitativa eu não consigo tirar essa produtividade, e no final a cobrança é a mesma, né?

Conforme se evidencia, expressando um nexo claro com a ética da sociedade de consumo e o ritmo veloz da hipermodernidade (BAUMAN, 2008), o regime 
produtivista que domina o trabalho acadêmico e seu modelo avaliativo compromete, sobremaneira, aspectos essenciais à reflexão e à construção do conhecimento (BOSI, 2018). Tais aspectos penalizam de forma mais extrema o enfoque qualitativo, conforme vimos, implantando disputas, fragmentação e impedindo alianças necessárias à pesquisa em domínios complexos como a saúde. Trata-se de um jogo em que o resultado, em muitos casos, vem sendo a perda da qualidade do que se produz, em face da inadaptabilidade ao modelo avaliativo, verificando-se ainda um crescente adoecimento dos atores envolvidos nesse modo de produção do conhecimento. Urge, portanto, uma nova ética, capaz de reverter essa "economia interna do campo" (BOURDIEU, 2004), possibilitando a tão propalada, mas pouco efetivada, interdisciplinaridade.

\section{Currículo e estratégias de ensino}

Neste tópico foram analisadas as falas das participantes a partir de duas principais dimensóes: como o tema pesquisa qualitativa aparece, ou deveria aparecer, nos currículos dos cursos de graduação ou pós-graduação e como estratégias de ensino inovadoras reverberam na formação dos estudantes.

No que se refere à primeira dimensão, apesar de terem sido mencionados pontos referentes à necessidade de maior articulação entre pesquisa qualitativa e prática profissional, bem como questôes sobre a alocação de professores não familiarizados em disciplinas que tratam da pesquisa qualitativa, as participantes apontam como problema a invisibilidade da temática nas grades curriculares da graduação e da pós-graduação dos cursos da área da saúde. Elas indicam três diferentes níveis de invisibilidade, que respectivamente desdobramos em subcategorias: ausência de qualquer tipo de disciplina; ausência de disciplinas obrigatórias e conteúdos qualitativos subsumidos em disciplinas de metodologia de pesquisa geral.

É possível observar pontos referentes à primeira subcategoria nas seguintes falas:

A gente ainda sente muito nossa fragilidade analítica.

Falta teoria social na pesquisa qualitativa.

O que que a gente tá fazendo nesse sentido? É, introduzindo na graduação, porque nós vimos tâo pouco na graduaçăo [sobre pesquisa qualitativa] [...] [foi quando] eu assumi a coordenaçáo de ensino do departamento de Odontologia e a disciplina de metodologia científica da graduaçáo ficou sem professor, eu precisei alocar um professor e fui me debruçar sobre o plano de ensino; aí que eu vi que não tinha nada de metodologia qualitativa e eu disse: "gente, mas, aí fica difícil", né? 
Nesta outra passagem também é possível visualizar a ausência de disciplinas que tratem da pesquisa qualitativa em função do predomínio da abordagem quantitativa nos currículos:

Pra mim, no melhor dos mundos, a pesquisa qualitativa seria algo que estaria inserida desde a graduação, com disciplinas que incentivem os alunos a conhecer outras vertentes que não só a pesquisa quanti. E também, isso atrelado com um currículo que mostre alguns referenciais teóricos, algumas abordagens.

As participantes reportam que em algumas instituiçóes existem disciplinas que tratam exclusivamente dos conteúdos pertinentes à pesquisa qualitativa, contudo, são de natureza eletiva. Por exemplo:

Outra coisa que eu penso que é importante, é que as disciplinas sejam obrigatórias, porque eu acho que tanto o aluno do mestrado quanto do doutorado, ele não sabe o que ele vai enfrentar depois, né? Se ele vai ter que orientar a iniciação [cientifica] [...] TCC na qualitativa ou na quantitativa. E fica assim, solto, quando é uma disciplina optativa, ele vem se ele já tem uma, um certo interesse, né? Mas principalmente no doutorado, eu penso que teria que ser uma disciplina obrigatória [...] que ele tem que sair dali doutor sabendo o mínimo.

Na medida em que determinada disciplina não é obrigatória, ela perde força dentro do processo de formação, pois elas tanto podem deixar de ser ofertadas em determinados momentos, quanto não serem escolhidas pelos estudantes nos semestres em que elas são ofertadas. Uma disciplina de natureza eletiva, portanto, é um indicativo da menoridade acadêmica da abordagem qualitativa (FRAGA et al., 2010).

Há relatos que apontam a presença da abordagem qualitativa em disciplinas obrigatórias, contudo, tais conteúdos aparecem subsumidos em meio a conteúdos relacionados à abordagem quantitativa, tal como podemos notar nos seguintes depoimentos:

Quando eu cheguei na USP, na Faculdade de Saúde Pública, eu não sabia que tinha uma professora que trabalhava com pesquisa qualitativa, porque eu lia as linhas de pesquisa e eu não conseguia encaixar, e não tinha ali expresso. Então, eu tive que ir atrás de professor, fazer contato pra aí eu saber [...]. Então, achei essa questão da divulgação também.

A gente tem uma disciplina que é dietética. Essa disciplina é pra ensinar o aluno a planejar um plano alimentar; antes era só nutrientes e como você contabiliza isso e faz o planejamento. É, com [essa professora] que a gente conseguiu colocar técnicas de pesquisa qualitativa dentro da disciplina, os alunos relatam pra gente como isso ampliou, como eles veem agora o indivíduo dentro de uma complexidade muito maior, que envolve bem-estar, que envolve percepção de corpo e não só o que ele ingere em termos de nutrientes, de calorias. 
$\mathrm{O}$ fato de encontrarmos conteúdos relativos à abordagem qualitativa em disciplinas obrigatórias de metodologia da pesquisa não altera a relação de prestígio nos currículos dos cursos que adotam essa estratégia, pelo contrário. Apesar de apresentar a temática à totalidade dos estudantes, e até mesmo vir a sensibilizar muitos deles, a complexidade das questôes que envolvem a produção de pesquisas qualitativas com rigor em um curtíssimo espaço de tempo gera, na grande maioria dos casos, uma percepçáo negativa sobre o processo de produção dentro dessa abordagem e, por contraste, uma percepção positiva em relação à abordagem quantitativa (BOSI, 2012a).

Em relação ao segundo enfoque, independentemente do espaço curricular destinado à temática da pesquisa qualitativa aos estudantes, as participantes deixam claro ser muito importante os professores dominarem não apenas o conteúdo a ser ensinado, mas também empregarem estratégias de ensino inovadoras que possam levar à superaçáo de alguns mal-entendidos sobre esse enfoque metodológico. Dois tipos de mal-entendidos são destacados: o mais comum é pensar que a pesquisa qualitativa se resume a uma técnica de coleta de dados diferente daquelas usadas na perspectiva quantitativa, como é possível perceber no seguinte depoimento:

A pessoa diz assim: "Vou fazer uma pesquisa quali e vou fazer grupo focal", mas não é isso que vem primeiro; "qual é o objeto de estudo e porque ele tem que ser estudado numa perspectiva qualitativa?”

A pesquisa qualitativa não se resume a métodos, não se resume a técnicas, e muitas vezes é passado pro graduando ou pós-graduando dessa forma, como se pesquisa qualitativa fosse você fazer pesquisa com técnicas diferentes da pesquisa quanti, e é um grande erro, né?

Já o segundo tipo de mal-entendido é curiosamente decorrente de uma tentativa de superar o primeiro: centrar as aulas na transmissão expositiva de correntes teóricas, conforme podemos perceber nos dois trechos abaixo.

Eu vejo que, às vezes, só o fato de ter esses encontros teóricos eles não são suficientes pra conseguir desenvolver as propostas que eles [os estudantes] têm.

[...][aula] tradicional expositiva, o professor apresentando o que que é a fenomenologia, o que que é o materialismo histórico dialético, mas quando a gente começa a experimentar e você traz estudos com aquilo aplicado, né? É aí que você aproxima isso pra realidade; você vê que [a pesquisa qualitativa] é uma forma, um método fundamental, que não é complementar, que não é inferior, né?

As estratégias que as participantes consideraram mais efetivas para a superação de tais mal-entendidos podem ser agrupadas em três subcategorias: estrutura e 
organização das aulas; inovação no modo de conduzir as atividades didáticas e rede de suporte didático-pedagógico aos docentes.

Com relação ao primeiro grupamento, é interessante destacar que as sugestôes vão desde alteraçóes de formato muito elementares, passando por uma organização que envolve o trabalho articulado entre estudantes de diferentes níveis de ensino, até mesmo a integração com projetos de extensão universitária, como é possível perceber, respectivamente, nos trechos abaixo:

A questáo do conhecimento entre pares, por exemplo, dos mestrandos ou doutorandos que estão no início pros que estáo saindo, dos mestrandos e doutorandos com os colegas da graduação, eu acho que essas trocas seriam bem interessantes.

[...] aproximar da pesquisa, o ensino e a extensão, porque vários trabalhos de extensão universitária, eles vão se valer [...] dos nossos instrumentos e técnicas da pesquisa qualitativa. Então, a gente tá aí aprendendo com a extensão a fazer a pesquisa qualitativa. Isso tem dado uma conversa muito importante.

Em que pese não haver literatura específica sobre o uso de estratégias didáticas relativas ao ensino da pesquisa qualitativa na graduação e na pós-graduação (BOSI, 2012a; SILVA; CASTRO-SILVA; MOURA, 2018), é interessante observar que as participantes consideram difícil, mas ao mesmo tempo fundamental, inovar na forma de conduzir as atividades didáticas. E tal inovação se materializaria com a adoção de atividades mais centradas no processo de aprendizagem dos estudantes do que no ensino de conteúdos estanques. Os depoimentos a seguir ilustram bem esta segunda subcategoria:

Nós íamos a campo fazer coleta, pra entender o que era uma pesquisa qualitativa, e era multidisciplinar, então não só tinha aluno da Enfermagem e tinha de vários outros países, então, a vivência e a roda era muito rica, porque tu via a experiência de outros países, de outros cursos; então, foi muito rica.

Os alunos realizam avaliação de um artigo, com instrumento, como se fosse aqueles itens do parecerista, só que bem trabalhadinho pra avaliar o estudo qualitativo. Aí, no segundo exercício, os alunos filmam uma entrevista com um adolescente, de dez a dezenove anos e aí leva essa entrevista pra sala de aula e a gente vai discutir de acordo com as técnicas de entrevista, né? Técnicas construídas assim, a partir de... não só de livros, de material de pesquisa, né? É de material acadêmico, mas também com nossa experiência [...]. Um outro exercício é a elaboraçáo de um projeto, que também é apresentado em sala.

Uma das participantes, logo após mencionar que "mestrado e doutorado não preparam para ser professor", defendeu enfaticamente a importância das metodologias ativas como uma estratégia inovadora para o ensino da pesquisa qualitativa: 
Eu tenho pena do professor que não tem estudado metodologia ativa. É, entáo assim, eu tenho investido... aí é um investimento pessoal, né? Não tem investimento da universidade; eu tenho feito cursos, tenho participado de eventos e buscado uma formação em metodologias ativas.

É possível perceber que as experiências relatadas estão de um modo ou outro inspiradas nas metodologias ativas, que tomam o estudante como protagonista do processo de ensino-aprendizagem por meio do seu engajamento crítico nas atividades propostas (MITRE et al., 2008; PAIVA et al., 2016). Como se trata de uma estratégia de aprendizagem pouca enraizada na prática docente universitária de um modo geral, e no ensino da pesquisa qualitativa de um modo específico, as participantes consideraram importante a construçáo de uma rede de suporte didático-pedagógico nacional e internacional para que os docentes possam compartilhar experiências e estratégias didático-pedagógicas.

Precisamos ter repositórios sobre o ensino de pesquisa qualitativa, não só publicações acadêmicas, mas também pra aportes [...]. Segundo, precisamos repositórios de vídeos. Eu acho que poderíamos fazer isso, para ajudar o ensino da pesquisa qualitativa.

A gente desenvolveu um projeto macro, com parcerias com outros professores de universidades federais [...]. Estudando o mesmo conteúdo, isso é importante, porque a gente tem partilhado de diversas experiências, pra convergir em um mesmo [...] potencial de crescimento, né?

De um modo geral, tanto o modo como as disciplinas aparecem, ou deveriam aparecer nos currículos de graduação e pós-graduação dos cursos da área da saúde, quanto as estratégias empregadas para o ensino da pesquisa qualitativa em saúde são afetadas pela posição subalterna desta temática na cultura acadêmica (SILVA; CASTRO-SILVA; MOURA, 2018). Para que tal quadro se reverta, é preciso que os atores nesse campo compreendam que a formação de pesquisadores qualitativos não depende apenas de um maior número de disciplinas ou de um maior repertório de estratégias didático-pedagógicas, ou ainda de uma rede de formação continuada mais robusta. Sem dúvida, todos estes pontos são fundamentais, mas é preciso levar em consideração o que afirma uma das participantes:

Eu sou uma pesquisadora e uma professora de pesquisa qualitativa, eu não sou professora de pesquisa. Eu sou uma pesquisadora, e ela tem que tá no meu dia a dia, lá na minha disciplina de graduação, na minha disciplina da pós, no meu grupo de pesquisa [...] trabalhar pesquisa é em qualquer disciplina ou em qualquer momento da formação do profissional. 
A formação do pesquisador qualitativo em saúde requer, portanto, uma prática docente que vá além das fronteiras da sala de aula, bem como um conceito mais alargado de currículo (TERIGI, 1996), tendo em vista que muitos deles serão formadores das futuras gerações de pesquisadores.

\section{Formação de educadores}

Nesta última categoria, foram organizadas as falas que tratam da formação de educadores em pesquisa qualitativa em saúde. Aqui sobressaem os aspectos críticos relacionados ao processo de formação desse pesquisador, que se resumem ao despreparo dos educadores para o ensino da pesquisa qualitativa em nossas universidades e à lacuna em formação interdisciplinar.

As participantes enfatizaram o limitado domínio dos fundamentos de pesquisa qualitativa em saúde por parte dos professores de pós-graduação, inclusive aqueles que ministram as disciplinas de pesquisa qualitativa. Elas relacionaram tal lacuna à deficiente formação básica em pesquisa e ao desafio da formação interdisciplinar (falta de conhecimento aprofundado das teorias sociais fundamentam as metodologias). Tal como apontado na literatura (BOSI, 2012a), isso também é reflexo do número reduzido de profissionais com formação consistente para a nucleação de grupos, a condução de pesquisas de alta qualidade e a orientação de mestres e doutores:

[...] eu acho que os docentes não têm experiência de fazer pesquisa qualitativa. [...] temos problemas muito sérios com muitos professores dos cursos de qualitativa.

[Na minha faculdade] o professor que está com menos carga horária, ministra metodologia. É complicado [...]. Para mim, enquanto professora de metodologia, é muito difícil conseguir ministrar aula sobre técnicas e métodos tâo variados.

Se eu não tenho uma formação concreta e sólida, quem irei formar e como será a qualidade dessa formação?

[...] na pós-graduação, normalmente os pesquisadores já estão vinculados a algum grupo de pesquisa. E muitas vezes, esse estudante entra vinculado com algum pesquisador, a maior parte tem sido assim, e a gente tem estimulado isso, admitindo inclusive que [...] é difícil formar alguém em vinte e quatro meses, mas é, esse é um desafio, talvez um dos maiores.

Nessa última fala, a participante traduz o que vem sendo apontado na literatura em relação ao modo individual do ensino (SILVA; CASTRO-SILVA; MOURA, 2018; VILLARDI; VERGARA, 2011) e assinala a barreira que o prazo exíguo impóe à complexa formação em pesquisa qualitativa. 
Foram também destacados desafios relacionados à mobilização e articulação de pesquisadores atuantes na área de pesquisa qualitativa em saúde, com a necessidade de organização de redes de pesquisadores, realização de eventos e projetos científicos conjuntos, dentre outros recursos.

A gente tem que fazer mais encontros de pesquisadores qualitativos, pra decidir isso que
estamos fazendo aqui: trocar experiências, se fortalecer, sair uma carta, uma moção, que
nem a gente faz nos congressos [...]. Estamos trabalhando isolados nas nossas universida-
des. Eu acho que uma rede de pesquisa qualitativa... não tem nenhuma no Brasil... Além
da rede, a gente tem que ter um projeto multicêntrico, em que toda a rede participasse,
porque daí você começa a ter mais visibilidade.

Essa busca de reconhecimento se justifica como estratégia de formação, uma vez que pretende superar guetos de conhecimento e integrar saberes, o que facilitaria o aprendizado complexo que se dá quando o capital cultural, científico e social de um grupo é compartilhado entre seus membros, potenciando a formação sólida de pesquisadores, que no futuro poderão ensinar (BOURDIEU, 1983).

\section{À guisa de conclusão}

No campo da saúde há vários desafios para a formação de pesquisadores em pesquisa qualitativa. Alguns desses desafios são estruturais, como a cultura acadêmica condicionada por fórmulas de avaliação de produtividade e o baixo investimento na preparação metodológica de cientistas da área, sobretudo com respeito às metodologias provenientes das ciências sociais. Além disso, outros entraves institucionais, como a ausência de disciplinas específicas, ou sua presença apenas em caráter optativo permeiam esse cenário. O impacto desse conjunto de fatores é a formação precária dos estudantes de pós-graduação, futuros pesquisadores do país. Condicionados às normas de avaliaçâo e curta duraçâo dos programas, além de receberem pouca formação, esses estudantes comumente limitam suas pesquisas qualitativas a relatos descritivos, contribuindo, involuntariamente, para a difusão da crença sobre a inferioridade científica da pesquisa qualitativa.

Esse entendimento preconceituoso se materializa numa versão de ensino da pesquisa qualitativa duplamente equivocada, na qual convivem intimamente a ideia simplista de que a técnica é o que define a pesquisa qualitativa, dando margem a um fetiche denominado "metodolatria" (CHAMBERLAIN, 2000; GASTALDO, 2012), e o senso comum de que a pesquisa qualitativa é uma abordagem fácil, já que 
nela tudo caberia e seria permitido, resultando muitas vezes em miscelâneas teóricopráticas que carecem de coerência e rigor (GASTALDO, 2018).

Concomitantemente, há importantes iniciativas que demarcam espaços de excelência e constituem núcleos de resistência à soberania do cientificismo. Neste estudo sobre a formação no Brasil, destacamos que, em alguns casos, encontramos o ensino da pesquisa qualitativa desde a graduaçáo, disciplinas obrigatórias de qualidade e ensino interdisciplinar, entre outras potencialidades descritas no quadro 1.

Quadro 1. Resumo de propostas de discentes e docentes para o desenvolvimento da formação em PQS no ensino superior brasileiro

\section{Em relaçáo aos aspectos estruturais estabelecidos no cenário nacional}

- Denunciar os efeitos específicos do domínio da biomedicina e da cultura produtivista para pesquisadores qualitativos, incluindo estratégias de promoção da saúde de docentes e discentes;

- Combater o preconceito de que a pesquisa qualitativa é de fácil realização ou se resume à aplicação de uma técnica de pesquisa;

- Criar e difundir critérios justos de avaliação de estudos e promoção de pesquisadores qualitativos (por exemplo, ver WEBSTER; GASTALDO, 2019);

- Oportunizar educação continuada para que pesquisadores qualitativos com excelência teórico-metodológica sejam formados como educadores.

Em relação aos aspectos institucionais estabelecidos nos programas de pós-graduaçáo e universidades

- Avaliar o que já é feito em todos os programas da saúde em cada universidade para criar estratégias de sustentabilidade da qualidade do ensino de pesquisa qualitativa, evitando duplicações entre programas e promovendo o ensino interdisciplinar;

- Se os docentes forem poucos ou carecerem de preparaçáo, criar alianças com programas de ciências sociais e humanas para oferecer fundamentação teórica para os estudantes;

- Assegurar uma sequência curricular para dar continuidade à formação dos estudantes (por exemplo, ensino de graduação, mestrado e doutorado em nível crescente de complexidade; conteúdos ou disciplina obrigatória desde a graduação; utilização de estudos qualitativos e quantitativos nas disciplinas da área específica do programa e parcerias com professores de metodologia quantitativa);

- Do ponto de vista pedagógico, utilizar múltiplas estratégias de ensino, incluindo metodologias ativas para promover competências teóricas e práticas, além de participar em redes de ensino e aprendizagem da pesquisa qualitativa em saúde.

Fonte: elaboração própria. 
Apesar de seus 120 anos de história e crescente expansão, a pesquisa qualitativa na área da saúde é recente e carece de consenso sobre sua natureza e qualidade (CRESWELL, 2014; LINCOLN; GUBA, 2000), havendo enorme riqueza de concepções teóricas e metodológicas ainda por ser ensinada nos programas de pósgraduação em saúde. Em nosso entendimento, o ensino interdisciplinar apresenta-se como uma abordagem propícia à qualificação e melhora da consistência teóricometodológica da produção cientifica nacional. Por outro lado, representa um desafio para o ensino e aprendizagem da pesquisa qualitativa, ao ser a educação interdisciplinar um movimento contra-hegemônico no atual contexto da avaliação disciplinar dos programas de pós-graduação.

O dilema de docentes e estudantes envolve a questão de como ensinar e aprender a produzir saberes relevantes para o entendimento e promoção da saúde coletiva e de um SUS de qualidade e, ao mesmo tempo, criar produtos que possam ser pontuados para que seus programas de pós-graduação ou eles mesmos não sejam penalizados por essas escolhas. ${ }^{1}$

\section{Referências}

ALMEIDA, M. M.; CONCEIÇÃO, M. I. G. O Sistema Único de Saúde e a política sobre drogas no Brasil. In: SUDBRACK, M. F. O. et al. (Orgs.). ABRAMD: compartilhando saberes. Brasília: Technopolitik, 2015. v. 1, p. 11-23.

ALMEIDA FILHO, N. de. Reconhecer Flexner: inquérito sobre produção de mitos na educação médica no Brasil contemporâneo. Caderno de Saúde Pública, Rio de Janeiro, v. 26, n. 12, p. 2234-2249, dez. 2010. Disponível em: <http://www.scielo.br/scielo.php?script=sci_ arttext\&pid=S0102-311X2010001200003\&lng=en\&nrm=iso>. Acesso em: 11 set. 2019. DOI: 10.1590/S0102-311X2010001200003.

BARBOUR, R.; KITZINGER, J. Developing focus group research: politics, theory and practice. Thousand Oaks: Sage, 1999.

BARROS, J. A. C. Pensando o processo saúde doença: a que responde o modelo biomédico? Saúde e Sociedade, São Paulo, v. 11, n. 1, p. 67-84, jul. 2002. Disponível em: <http://www. scielo.br/scielo.php?script=sci_arttext\&pid=S0104-12902002000100008\&lng=en\&nrm=iso >. Acesso em: 11 set. 2019. DOI: 10.1590/S0104-12902002000100008.

BAUMAN, Z. Vida para consumo: a transformação das pessoas em mercadoria. Rio de Janeiro: Zahar, 2008. 
BERG, M. B.; SEEBER, B. K. The slow professor: challenging the culture of speed in the academy. Transformative Dialogues: Teaching \& Learning Journal, v. 6, n. 3, p. 1-7, Apr. 2013. Disponível em: <https://www.kpu.ca/sites/default/files/Teaching\%20and\%20Learning/ TD.6.3.5_Berg\%26Seeber_Slow_Professor.pdf> Acesso em: 7 set. 2019. DOI: 10.1590/S010412902002000100008 .

BERNARDO, M. H. Produtivismo e precariedade subjetiva na universidade pública: o desgaste mental dos docentes. Psicologia \& Sociedade, Belo Horizonte, v. 26, n. esp., p. 129139,2014. Disponível em: <http://www.scielo.br/scielo.php?script=sci_arttext\&pid=S010271822014000500014\&lng=en\&nrm=iso >. Acesso em: 11 set. 2019. DOI: 10.1590/S010271822014000500014 .

BOSI, A. P. M. Avaliação como forma atualizada de dominação e intensificação do trabalho. Revista Movimento em Debate, v. 2, n. 3, p. 26-37, 2009.

BOSI, M. L. M. Formar pesquisadores qualitativos em saúde sob o regime produtivista: compartilhando inquietaçôes. In: CHAPELA MENDOZA, M. C. et al. (Org.). Formación en investigación cualitativa critica en salud: Abriendo caminos en Latinoamérica. Xochimilco: Universidade Autónoma Metropolitana, 2018. p. 161-179.

Pesquisa qualitativa em saúde coletiva: panorama e desafios. Ciência \& Saúde Coletiva, Rio de Janeiro, v. 17, n. 3, p. 575-586, mar. 2012a. Disponível em: <http://www.scielo.br/scielo. php?script=sci_arttext\&pid=S1413-81232012000300002\&lng=en\&nrm=iso $>$. Acesso em: 11 set. 2019. DOI: 10.1590/S1413-81232012000300002.

- Produtivismo e avaliação acadêmica na Saúde Coletiva brasileira: desafios para a pesquisa em Ciências Humanas e Sociais. Caderno de Saúde Pública, Rio de Janeiro, v. 28, v. 2, p. 2387-2392, dez, 2012b.

BOURDIEU, P. A miséria do mundo. 8. ed. Petrópolis: Vozes, 2011.

. O campo científico. In: ORTIZ, R. (Org.). Pierre Bourdieu. São Paulo: Ática, 1983. p. $122-155$.

Os usos sociais da ciência: por uma sociologia clínica do campo. São Paulo: Editora Unesp, 2004.

BRAUN, V.; CLARKE, V. Using thematic analysis in psychology. Qualitative Research in Psychology, v. 3, n. 2, p. 77-101, 2006. Disponível em: <https://www.tandfonline.com/doi/ abs/10.1191/1478088706qp063oa>. Acesso em: 7 set 2019.

CAMPOS, R. O. Fale com eles! O trabalho interpretativo e a produção de consenso na pesquisa qualitativa em saúde: inovaçóes a partir de desenhos participativos. Physis, Rio de Janeiro, v. 21, n. 4, p. 1269-1286, dez. 2011. Disponível em: http://www.scielo.br/scielo.php?script=sci_ arttext\&pid=S0103-73312011000400006\&lng=en\&nrm=iso. Acesso em: 11 set. 2019. DOI: $10.1590 /$ S0103-73312011000400006. 
CENTRE for Critical Qualitative Health Research (2018, May 24). What is 'Critical'? Disponível em: https://ccqhr.utoronto.ca/about-cq/what-is-critical/. Acesso em: 25 jul. 2020.

CHAMBERLAIN, K. Methodolatry and qualitative health research. Journal of Health Psychology, [S.l.], v. 5, n. 3, p. 285-296, 2000. Disponível em: <https://journals.sagepub.com/doi/pdf/10.1 177/135910530000500306>. Acesso em: 11 dez. 2019. DOI: 10.1177/135910530000500306.

CHAPELA, M. del C. Formación de investigadores críticos en salud. Una esperanza para la salud latinamericana. In: CHAPELA, Maria del Consuelo et al. (Org.). Formación en investigación cualitativa critica en salud: Abriendo caminos en Latinoamérica. Xochimilco: Universidade Autònoma Metropolitana, 2018. p. 7-21.

CHIZZOTTI, A. Pesquisa qualitativa em ciências humanas e sociais. Petrópolis: Vozes, 2008.

CRESWELL, J. W. Investigação qualitativa e métodos de pesquisa: escolhendo entre cinco abordagens. 3.ed. Porto Alegre: Penso, 2014.

EAKIN, J. M. Educating critical qualitative health researchers in the land of the randomized controlled trial. Qualitative Inquiry, v. 22, n. 2, p. 107-118, Dec. 2016.

FACEY, M.; GLADSTONE, B.; GASTALDO, D. Qualitative Health Research: An introduction. In: FACEY, M. et al. (Eds). Learning and Teaching Qualitative Health Research in Ontario: A Resource Guide. Toronto: E-Campus Ontario Publication, 2018. Disponível em: <http://qualitativeresearchontario.openetext.utoronto.ca/> Acesso em: 27 ago. 2019.

FRAGA, A. B. et al. Alteraçôes curriculares de uma escola septuagenária: um estudo sobre as grades dos cursos de formação superior em educação física da ESEF/UFRGS. Movimento, Porto Alegre, v. 16, n. esp., p. 61-95, 2010.

GASTALDO, D. Ensinando pesquisa qualitativa em saúde no Canadá: alguns avanços e novos desafios Ciência \& Saúde Coletiva, Rio de Janeiro, v. 17, n. 3, p. 591-593, mar. 2012.

Epistemological congruence and rigour in qualitative research [video]. Toronto: Centre for Critical Qualitative Health Research, University of Toronto, jul. 2018. Disponível em: <https://www.youtube.com/watch?v=BpgyxPx0RC8>. Acesso em out. 2019.

GASTALDO, D.; BOSI, M. L. ¿Qué significa tener impacto? Los efectos de las políticas de productividad científica en el area de la salud. Enfermería Clínica, v. 20, n. 3, p. 145-146, May 2010.

HOLLIGAN, C. Becoming a researcher: forms of capital associated with "research capacity" trajectories of young British social anthropologists. International Journal of Qualitative Studies in Education, London, v.28, n. 10, p. 1249-1270, Nov. 2015.

KERR-PONTES, L. R. S. et al. Uma reflexão sobre o processo de avaliação das pós-graduaçóes brasileiras com ênfase na área de saúde coletiva. Physis, Rio de Janeiro, v. 15, n. 1, p. 83-94, jun. 2005. Disponível em: DOI: 10.1590/S0103-73312005000100005. Acesso em: 17 set. 2019. 
KRUEGER, R. Developing questions for focus groups. In: MORGAN, D.; KRUEGER, R. (Eds.). The focus group kit. Thousand Oaks: Sage, 1997. v. 3.

LIMA, N. T.; SANTANA, J. P. (Org.). Saúde Coletiva como compromisso. A trajetória da Abrasco. Rio de Janeiro: Fiocruz/ABRASCO, 2006.

LINCOLN, Y. S.; GUBA, E. G. Paradigmatic controversies, contradictions, and emerging confluences. In: DENZIN, Norman K.; LINCOLN, Yvonna S. (Eds.). The handbook of qualitative research. Thousand Oaks: Sage, p. 1065-1122, 2000.

LUZ, M. T. O futuro do livro na avaliação dos programas de pós-graduação: uma cultura do livro seria necessária? Interface, Botucatu, v. 9, n. 18, p. 631-636, 2005 b.

. Prometeu acorrentado: análise sociológica da categoria produtividade e as condiçóes atuais da vida acadêmica. Physis, Rio de Janeiro, v. 15, p. 39-57, 2005 a.

MALTERUD, K. Theory and interpretation in qualitative studies from general practice: why and how? Scandinavian Journal of Public Health, v. 44, n. 2, p. 120-129, 2016.

MERCADO, F. J.; BOSI, M. L. M. Pesquisa qualitativa: notas para um debate. In: BOSI, M. Lucia M.; MERCADO, Fernando J. M. (Orgs.). Pesquisa qualitativa de serviços de saúde. Petrópolis: Vozes, 2010. p. 29-60.

MERCADO, F. J.; GASTALDO, D.; PRADO, M. L. Colaboração Ibero-americana em Pesquisa Qualitativa em Saúde: desafios e perspectivas. Texto \& Contexto, v. 27, n. 3, 2018. Disponível em: <http://www.scielo.br/pdf/tce/v27n3/0104-0707-tce-27-03-editorial.pdf> Acesso em: 11 set. 2019.

METZE, K. Bureaucrats, researchers, editors, and the impact factor: a vicious circle that is detrimental to science. Clinics, São Paulo, v. 65, n. 10, p. 937-940, 2010.

MITRE, S. M. et al. Metodologias ativas de ensino-aprendizagem na formação dos profissionais de saúde: debates atuais. Ciência \& Saúde Coletiva, Rio de Janeiro, v. 13, n. 2, p. 2133-2144, 2008.

PACKER, M. The science of qualitative research. Cambridge: Cambridge Press, 2011.

PAIM, J. S. Desafios para a saúde coletiva no século XXI. Salvador: EDUFBA, 2006.

PAIVA, M. R. F. et al. Metodologias ativas de ensino-aprendizagem: revisão integrativa. Sanare, v. 15, n. 2, p. 145-153, jun/dez, 2016.

PRASAD, P. Crafting qualitative research: working in the postpositivist traditions. New York: M. E. Sharpe Inc. 2005.

POUPART, J. et al. A pesquisa qualitativa: enfoques epistemológicos e metodológicos. Petrópolis: Vozes, 2010. 
RAMOS, F. R. S. et al. A eticidade na pesquisa qualitativa em saúde: o dito e o não dito nas produçôes científicas. Ciência \& Saúde Coletiva, Rio de Janeiro, v. 15, supl. 1, p. 1673-1684, jun. 2010. Disponível em: http://www.scielo.br/scielo.php?script=sci_arttext\&pid=S141381232010000700079\&lng=en\&nrm=iso. Acesso em: 8 set. 2019. DOI: 10.1590/S141381232010000700079 .

SILVA, A. da; CASTRO-SILVA, C. R.; MOURA, L. de. Pesquisa qualitativa em saúde: percursos e percalços da formação para pesquisadores iniciantes. Saúde e Sociedade, São Paulo, v. 27, n. 2, p. 632-645, jun. 2018. Disponível em: <http://www.scielo.br/scielo.php?script=sci_ arttext\&pid=S0104-12902018000200632\&lng=en\&nrm=iso>. Acesso em: 6 set. 2019.

TERIGI, F. Notas para uma genealogia do currículo escolar. Educação e Realidade, Porto Alegre, v. 1, n. 1, p. 159-186, fev. 1996.

VILLARDI, B. Q.; VERGARA, S. C. Implicações da aprendizagem experiencial e da reflexão pública para o ensino de pesquisa qualitativa e a formação de mestres em administração. Revista de Administração contemporânea, Curitiba, v. 15, n. 5, p. 794-814, 2011. Disponível em: <http:// www.scielo.br/scielo.php?script=sci_arttext\&pid=S1415-65552011000500002\&lng=en\&nrm= iso>. Acesso em: 11 set. 2019.

WEBSTER, F. et al. Doing science differently: A framework for assessing the careers of qualitative scholars in the health sciences. International Journal of Qualitative Methods, v. 18, p. 1-7, 2019. Disponível em: <https://journals.sagepub.com/doi/pdf/10.1177/1609406919838676> Acesso em: 11 set. 2019.

\section{Nota}

${ }^{1}$ M. I. G. Conceição e D. Gastaldo: revisão de literatura, estruturação do artigo, coleta e análise de dados, construção das categorias de análise, análise de categorias, redação e revisão final do manuscrito. A. B. Fraga: estruturação do artigo, coleta e análise de dados, construção das categorias de análise, análise de categorias, redaçáo e revisão final do artigo. M. L. M. Bosi: concepçáo, teorização, processamento, categorização e análise do material discursivo e redação do artigo. L. MagaIhães e T. de Andrade: coleta e análise de dados, análise das categorias, redação e revisão do manuscrito. R. R. Lago: análise de dados, análise de categorias, redação do artigo. 


\section{Abstract}

\section{Educating qualitative health researchers in Brazil: students and teachers' perspectives}

Although expanding rapidly, qualitative research faces challenges in the health field. The objective is to analyze the teaching of qualitative research in health in graduate studies in Brazil from the perspective of actors involved in the process, aiming to understand challenges and possibilities in the education of future researchers. Three focus groups were conducted with 37 participants in the space of a qualitative health research conference. Four categories emerged in the analysis: biomedical scientific field; productivism and academic evaluation; teaching strategies, and curriculum and educator training. The results reveal challenges in the education of researchers in qualitative research in Brazil in a scientific field dominated by the positivist tradition, low literacy of scientists in qualitative methods and a predominance of academic productivist culture. It is concluded that prejudice hinders the education of new researchers, but there are initiatives of excellence in training, such as the mandatory teaching of this approach at undergraduate courses and interdisciplinary education at graduate level.

Keywords: qualitative research; researchers training; education; scientific productivity. 